\title{
Avaliação das características morfológicas mudas de cajueiro sob déficit hídrico em condições de Semiárido paraibano
}

\section{Evaluation of morphological characteristics of cashew seedlings under drought in semi- arid conditions Paraiba}

\author{
Isidro Patrício de Almeida Neto ${ }^{1 *}$, Marlon Laynon de Andrade ${ }^{2}$, José da Silva Sousa ${ }^{3}$, Saulo Soares da Silva ${ }^{4}$, Anderson \\ Bruno Anacleto de Andrade
}

Resumo: O objetivo do trabalho foi avaliar as características morfológicas do cajueiro (Anacardium occidentale L) submetido a déficit hídrico na fase de porta-enxerto. O trabalho foi executado na Universidade Federal de Campina Grande, Campus Pombal - PB. Realizou-se o trabalho em casa de vegetação, em delineamento inteiramente casualizado, com cinco tratamentos e quatro repetições, sendo os tratamentos compostos de cinco diferentes lâminas de irrigação (60, 80, 100 , 120 e 140 $\mathrm{ml} / \mathrm{dia} / \mathrm{saco}$ ). O experimento teve início no dia 27 de Junho de $2013 \mathrm{com}$ fim no dia 15 de Agosto de 2013. Foram avaliadas as seguintes variáveis: altura média das plantas $(\mathrm{cm})$, diâmetro médio do caule $(\mathrm{mm})$, o número médio de folhas. Foram utilizados sacos plásticos (volume de $1 \mathrm{~L}$ ) onde estes foram cheios com solo franco arenoso não salino $\left(\mathrm{pH}=8,23 ; \mathrm{CE}=0,03 \mathrm{ds} . \mathrm{m}^{-1}\right), \mathrm{e} 2 \%$ de esterco bovino curtido. Inicialmente o solo foi colocado em capacidade de campo. O trabalho pôde mostrar que as lâminas de irrigação pouco influenciaram nas características avaliadas nas mudas de cajueiro.

Palavras-chaves: Anacardium occidentale L; Laminas de irrigação; Diâmetro do caule; Germinação.

\begin{abstract}
The objective was to evaluate the morphological characteristics of cashew (Anacardium occidentale L.) subjected to water deficit in the rootstock phase. The work was performed at the Federal University of Campina Grande, Campus Pombal PB. We carried out the work in a greenhouse, in a randomized design, with five treatments and four replications, with the treatments composed of five different water depths (60, 80, 100, 120 and $140 \mathrm{ml} /$ day / bag). The trial began on 27 June 2013 to end on 15 August 2013. The following variables were evaluated: average plant height (cm), stem diameter (mm), the average number of leaves. Plastic bags were used (volume $1 \mathrm{~L})$ where they were not filled with saline sandy loam soil $(\mathrm{pH}=$ $8.23 ; \mathrm{EC}=0.03 \mathrm{dS} . \mathrm{m}-1$ ), and $2 \%$ of cattle manure. Initially, the field soil was placed in capacity. The work could show that little irrigation levels influenced the characteristics evaluated in cashew seedlings.
\end{abstract}

Key words: Anacardium occidentale L; Blades irrigation; Stem diameter; Germination.

\footnotetext{
*Autor para correspondência

Recebido para publicação em 20/12/2014; aprovado em: 03/02/2015

${ }^{1}$ Mestrando em Sistemas Agroindustriais, Universidade Federal de Campina Grande, Pombal, (83)999006665; E-mail: isidroneto2@ gmail.com

${ }^{2}$ Mestrando em Sistemas Agroindustriais, Universidade Federal de Campina Grande, Pombal, E-mail: isidroneto2@gmail.com

${ }^{3}$ Mestre em Sistemas Agroindustriais, Universidade Federal de Campina Grande, E-mail: silva_agronomo@hotmail.com

${ }^{4}$ Mestrando em Sistemas Agroindustriais, Universidade Federal de Campina Grande, Pombal, (83)999083364, E-mail: saulosoares90@ gmail.com;

${ }^{5}$ Aluno de Graduação em Agronomia, UFCG/CCTA, Pombal-PB; bdeandrade3@gmail.com
} 


\section{INTRODUÇÃO}

A cultura do caju, anualmente, gira em torno de 2,4 bilhões de dólares e com isso ganhando força no agronegócio mundial. Entretanto, no Brasil a exportação está sendo o grande foco da produção de castanha e derivados do caju, sendo a América do Norte um dos maiores consumidores destes produtos (OLIVEIRA, 2003).

O caju apresenta resistência a climas secos e está muito bem adaptado a regiões tropicais. Sendo que o nordeste brasileiro concentra os maiores produtores da fruta no país. Como uma boa fonte de alimento o caju apresenta elevados teores de vitaminas, e fonte de energia (BARROS, 2004). Na região nordeste o caju é economicamente uma cultura de grande importância assim como em todo o país, e com isso afetando setores como geração de emprego, renda, investimentos e ao mesmo tempo reduzindo o êxodo rural, através da oportunidade de emprego na entressafra (AGUIAR, 2000).

Tradicionalmente, a cultura do caju é resistente e adaptada à seca, desenvolvendo-se até em condições altamente diversas, com isso para muitos não é interessante estudos para verificar se a cultura responderia bem à irrigação (OLIVEIRA, 2002). Paiva et al. (1991) trabalhando com caju demonstraram que no Brasil tem se buscado um maior aproveitamento do pedúnculo com utilização em diversos setores como na pecuária na complementação de 3 rações e também com os produtos, como sucos, sorvetes, doces, licores, mel, geleia, cajuína, refrigerantes gaseificados e aguardentes.

O cajueiro (Anacardium occidentale L.) é uma espécie tropical nativa do Brasil, que se encontra dispersa em quase todo seu território (CAVALCANTI et al.; 2008). É considerada uma das frutíferas tropicais de maior importância, constituindo-se como alternativa econômica para grande número de países inseridos nas zonas equatoriais do globo (MELO FILHO et al., 2006; CRISÓSTOMO et al., 2001).

A água é essencial em todas as etapas da produção de diversos cultivos, no entanto, considerando a grande irregularidade da distribuição de chuvas que ocorre na região Nordeste do Brasil, este fato tem contribuído ainda mais para os baixos rendimentos obtidos com o cultivo do cajueiro (CRISÓSTOMO, 2001). Além da quantidade, a qualidade da água também é importante, pois o aumento de salinidade, presente na mesma, pode reduzir a absorção de nutrientes e causar sérios danos ao estabelecimento da planta. Desta forma a utilização da irrigação possibilitar a manutenção da umidade do solo em padrões adequados de forma que a cultura possa expressar o seu potencial produtivo (OLIVEIRA, 1999).

O cajueiro responde significativamente à irrigação, sendo que a produtividade do cajueiro anão precoce irrigado pode alcançar $4.600 \mathrm{~kg}$ de castanhas por hectare, no quarto ano de produção, com um incremento de $1.153 \%$ em relação ao cajueiro comum sob sequeiro, e ter o período de colheita ampliado para dez meses (OLIVEIRA et al., 1997). São relativamente vastas as informações disponíveis da fenologia do cajueiro em regime de sequeiro, por outro lado, em regime de irrigação durante a formação do porta-enxerto, as informações são ainda limitadas.

O objetivo do trabalho foi avaliar as características morfológicas do cajueiro (Anacardium occidentale L) submetido a déficit hídrico na fase de porta-enxerto.

\section{MATERIAL E MÉTODOS}

O trabalho foi executado na Universidade Federal de Campina Grande, Campus Pombal - PB. Realizou-se o trabalho em casa de vegetação, em delineamento inteiramente casualizado, com cinco tratamentos e quatro repetições, sendo os tratamentos compostos de cinco diferentes lâminas de irrigação $(60,80,100,120$ e $140 \mathrm{ml} / \mathrm{dia} / \mathrm{saco})$. O experimento teve início no dia 27 de Junho de 2013 com fim no dia 15 de Agosto de 2013.

Foram avaliadas as seguintes variáveis: altura média das plantas $(\mathrm{cm})$, diâmetro médio do caule $(\mathrm{mm})$, o número médio de folhas. Foram utilizados sacos plásticos (volume de $1 \mathrm{~L}$ ) onde estes foram cheios com solo franco arenoso não salino ( $\mathrm{pH}=8,23 ; \mathrm{CE}=0,03 \mathrm{ds} \cdot \mathrm{m}^{-1}$ ), e $2 \%$ de esterco bovino curtido. Inicialmente o solo foi colocado em capacidade de campo.

As sementes de caju foram semeadas diretamente nos sacos utilizando-se apenas uma semente por saco, uma vez que, segundo Cavalcanti Júnior (2001), a germinação das castanhas/sementes gira em torno de $95 \%$, quando elas são de boa qualidade. As castanhas foram postas para germinar em posição vertical, com o ponto de incisão castanha/pedúnculo voltado para cima e a uma profundidade de $3 \mathrm{~cm}$ da superfície do substrato. O controle da irrigação foi realizado quatro dias após a semeadura com lâminas de irrigação indicados anteriormente. A irrigação era realizada uma vez por dia ao final da tarde, e duas vezes por dia em períodos mais quentes. As avaliações foram realizadas duas vezes. Aos 15 e 30 após a emergência das plantas.

As características variáveis analisadas em 30 dias após a germinação foram altura de plantas, em que se mediu com régua graduada do colo das plântulas até a extremidade superior da última folha, o diâmetro do caule, medido com um paquímetro a dois centímetros do solo, o número de folhas.

\section{RESULTADOS E DISCUSSÃO}

O propósito fundamental da irrigação é fornecer água às plantas de acordo com a necessidade das plantas, de maneira que se consiga otimizar a produção em quantidade e qualidade. Assim, se faz necessário repor a água do meio antes que a quantidade de água no solo seja inferior à quantidade demandada pela evapotranspiração fazendo com que a deficiência de água venha influenciar a produção (BERNARDO et al., 2008).

Castro Neto (2003) ressalta que considerando o comportamento da resistência estomática durante o período de déficit hídrico, constata-se que a resistência das folhas expostas ao sol é maior em períodos de irrigação sugerindo que, ao sair de um déficit hídrico, a planta começa com uma economia de água como forma de adaptação, mas, ao continuar a irrigação, esta resistência tende a decrescer.

As lâminas de irrigação pouco influenciaram nas características avaliadas nas mudas de cajueiro. Nas tabelas 1 e 2 estão representados os dados avaliados no cajueiro durante 15 e 30 dias após a emergência (DAE) respectivamente. Para número de folhas, a lâmina que proporcionou o maior número de folhas na analise realizada nos 15 DAE foi a $120 \mathrm{ml}$ (Tabela 1), para diâmetro do caule, a lâmina de $100 \mathrm{ml}$ foi maior diâmetro e para altura da planta, a lâmina de $140 \mathrm{ml}$ que proporcionou maior altura de planta. 
Tabela 1. Número de folhas, diâmetro do caule e altura de planta de cajueiro aos 15 DAE, em função de distintos déficits hídricos, Pombal - PB, 2013.

Avaliação feita aos 15 DAE

\begin{tabular}{cccc}
\hline Lâmina de água $(\mathbf{m l})$ & Número de folhas & Diâmetro do caule (mm) & Altura da planta (cm) \\
\hline 60 & 6,75 & 4,85 & 9,23 \\
80 & 5,33 & 4,7 & 8,00 \\
100 & 6,65 & 5,6 & 8,74 \\
120 & 8,55 & 4,9 & 9,47 \\
140 & 5,50 & 5,0 & 10,35 \\
\hline
\end{tabular}

Para as análises realizadas aos 30 DAE (Tabela 2), ocorreu um maior número de folhas quando se aplicou a lâmina $100 \mathrm{ml}$, para diâmetro do caule, a lâmina de $60 \mathrm{ml}$ foi a que proporcionou maior diâmetro do caule e para altura da planta, a lâmina de $140 \mathrm{ml}$ que proporcionou maior altura de planta.

Tabela 2. Número de folhas, diâmetro do caule e altura de planta de cajueiro coletadas aos 30 DAE, em função de distintos déficits hídricos, Pombal - PB, 2013.

\begin{tabular}{cccc}
\hline & \multicolumn{3}{c}{ Avaliação feita aos 30 DAE } \\
\hline Lâmina de água $(\mathbf{m l})$ & Número de folhas & Diâmetro do caule (mm) & Altura da planta (cm) \\
\hline 60 & 8,25 & 5,85 & 11,17 \\
80 & 6,75 & 5,10 & 9,26 \\
100 & 9,0 & 5,65 & 12,15 \\
120 & 8,5 & 5,23 & 10,33 \\
140 & 8,5 & 5,53 & 14,23 \\
\hline
\end{tabular}

Um dos motivos para ocorre essa variação na lâmina de irrigação, para as características avaliadas, é a quantidade de reserva contida na castanha semeada, visto que, uma castanha de porte maior, teoricamente, contém uma quantidade maior de reserva, favorecendo um desempenho mais vigoroso da plântula. Isso pode explicar a variação nas variáveis numa mesma lâmina de água quando comparada entre os dias de avaliação.

\section{CONCLUSÃO}

O referente trabalho pôde mostrar que as lâminas de irrigação pouco influenciaram nas características avaliadas nas mudas de cajueiro.

\section{REFERÊNCIAS BIBLIOGRAFICAS}

BERNARDO, S.; SOARES, A. A.; MANTOVANI, E. C. Manual de Irrigação. 8 ed. Viçosa: UFV, 2008. 625p.

CAVALCANTI, M. L. F.; FERNANDES, P. D.; GHEYI, H. R.; BARROS JÚNIOR, G. Fisiologia do cajueiro anão precoce submetido à estresse hídrico em fases fenológicas. Revista de Biologia e Ciências da Terra, Paraíba - PB, v. 8, n. 1, p. 42-53, 2008.

CAVALCANTI JÚNIOR, A.T.; CHAVES, J.C.M. Produção de mudas de cajueiro. Fortaleza: EMBRAPA-CNPAT, 2001. 43p. (Documentos, 42).
CASTRO NETO, M.T. de. Efeito do déficit hídrico na transpiração e resistência estomática da mangueira. Revista Brasileira de Fruticultura, v.25, n 1, p.93-95, 2003.

CRISÓSTOMO, L. A.; SANTOS, F. J. de S.; OLIVEIRA, V. H. de; RAIJ, B. V.; BERNARDI, A. C. de C.; SILVA, C. A.; SOARES; I. Cultivo do Cajueiro Anão Precoce: aspectos fitotécnicos com ênfase na adubação e na irrigação. Fortaleza: Embrapa Agroindústria Tropical, 2001. 20p. (Embrapa Agroindústria Tropical. Circular Técnica, 8).

MELO FILHO, O. M. de; COSTA, J. T. A.; CAVALCANTE JÚNIOR, A. T.; BEZERRA, M. A.; MESQUITA, R. C. M. Caracterização biométrica, crescimento de plântulas e pega de enxertia de novos porta-enxertos de cajueiro anão precoce. Revista Ciência Agronômica, Fortaleza CE, v. 37, n. 3, p. 332- 338, 2006.

OLIVEIRA, V. H.; SAUNDERS, L. C. U.; PARENTE, J. I. G.; ALMEIDA, J. I. L.; MONTENEGRO, A. A. T. Comportamento do Cajueiro Comum e Anão Submetido a Diferentes Tensões de Água no Solo. Fortaleza: EMBRAPA-CNPAT, 1996a. 4 p. (EMBRAPA CNPAT, Pesquisa em Andamento,19).

OLIVEIRA, V. H. de. Caracterização de clones de cajueiro anão-precoce (Anacardium occidentale L.) sob diferentes regimes hídricos. 1999. 94 f. Tese (Doutorado em Agronomia) - Universidade Federal do Ceará, Fortaleza. 